\title{
Etiology of Maternal Mortality at Nepalgunj Medical College
}

\author{
$B C D^{1}$, Neupane $G P^{2}$, Rai $M^{3}$, Sharma $A^{4}$
}

\begin{abstract}
Introduction: Maternal mortality is an indicator of the quality of obstetric care in a community directly reflecting the utilization of health care services available. Maternal mortality has been recognised as a public health problem in the developing countries. Aim and Objective: To analyse the etiology of maternal deaths. Material and Methods: This descriptive study was conducted in the gynaecology and obstetrics department of the Nepalgunj Medical College Teaching Hospital Banke Nepal for a period of two years from august 2016-august 2018. All cases of maternal deaths in line with the definition of World Health Organization have been included. Data were collected and analyzed. Results: Twenty three (23) maternal deaths were identified during the study period. $69.56 \%$ of deaths occurred due to direct obstetric causes. Uncontrollable postpartum haemorrhage with $37.5 \%$ was the leading cause of maternal death followed by eclampsia (18.75\%) and sepsis (18.75\%). Indirect causes were dominated by heart disease. Maximum 56.5\% of deaths had occurred after 48 hours of admission. Conclusions: Haemorrhage, eclampsia and infections are the main causes of maternal deaths in our study. Majority of the deaths are preventable by proper antenatal care, counselling and asepsis practice, access to emergency medication, transfusion and anaesthetic and surgical teams in hospitals but also through the involvement of religious leaders, traditional and any community to better understand the population obstacles to reducing maternal mortality.
\end{abstract}

Key words: Etiology, maternal mortality, prenatal care.

\section{INTRODUCTION}

Maternal mortality is defined according to the World Health Organization (WHO) as the death of a woman while pregnant or of within 42 days after delivery, regardless of length or location, from any cause related to or aggravated by the pregnancy or its management but not from accidental or incidental causes ${ }^{1}$.

Each year around 358,000 women die because of complications during pregnancy or childbirth and many more encounter serious problems in women. The vast majority of these problems occur in developing countries, where poverty increases sickness and reduces access to maternal care. These deaths occur within a context of gender-based, economic, political and cultural discrimination and neglect of women's right to equal status and equitable access to maternal health services ${ }^{2}$.

The patterns of maternal mortality (MM) reveal large difference between and within countries $99 \%$ of maternal

1. Dr. Durga B.C.

2. Dr. Ganesh Prasad Neupane

3. Dr. Maya Rai

4. Dr. Aseem Sharma

Address for correspondence:

Dr. Durga B. C.

Department of Obst. \& Gynae.

Nepalgunj Medical College, Kohalpur

Banke, Nepal

E-mail:durgabc53@gmail.com deaths occur in developing countries and only $1 \%$ of deaths in developed countries ${ }^{3}$. Traditionally and culturally, pregnancy is considered to be natural in Nepal. Thus, regular check-ups are thought to be unnecessary, particularly in rural areas, unless there are complications. It have been found that some groups of women in Nepal do not seek prenatal care (PC) because they think infants were more likely to die if they do so while these infants were in the womb. Such norms were found in other developing countries like Egypt, as well. Women's as well as their families' (especially husbands and mother-in-laws) perception about MHS were averting women from receiving prenatal care, thus, increasing risk of maternal mortality ${ }^{2}$.

In Nepal many district hospitals are unable to cope with obstetric emergencies, drugs are not always readily available in the pharmacy and if available, the poor families are unable to buy. In addition, the health care staffs in the rural health posts are often reported as being unreliable, hostile towards local patients, and absent from the care centres; the major probable causes of not seeking medical care by rural women even when medical care was available. These factors also attribute maternal mortality ${ }^{4}$.

Even above mentioned factors play important role, maternal mortality is high even at tertiary care hospital of Nepal. Hence to reduce maternal mortality it's very necessary to identify the cause of it. This study is proposed to analyse the etiology of maternal mortality in the tertiary care hospital of Nepalgunj medical college teaching hospital Kohalpur Banke Nepal.

MATERIAL AND METHOD

This descriptive study was conducted in the gynaecology and 
obstetrics department of the Nepalgunj Medical college teaching hospital Banke Nepal for a period of two years from August 2016 - August 2018. The study population consisted of any woman who died during pregnancy or within 42 days of delivery. All maternal deaths recorded and identified by the gynaecology and obstetrics department of Nepalgunj Medical College Teaching Hospital Kohalpur August 2016 until august 2018 and meeting the definition of the World Health Organization has been included in this study and woman brought dead was excluded. The literature review of the different registers by using a pre-established questionnaire was conducted to collect data and related socio-demographic variables, the concept of antenatal monitoring, gestational age, circumstances and time of occurrence of death. Prior authorization had been obtained from the Ethical Committee of the Institute.

\section{RESULTS:}

The Mean age of women who died because of pregnancy related cause was $24.35 \pm 5.882$, minimum age was 16 years and maximum age was 40 year and maximum women were in the age range of $20-30$ years $(65.22 \%)$.

Analysis of socioeconomic status shows that most of the women 19 (82.60\%) had lower socioeconomic status and most of the women $17(73.91 \%)$ had education up to primary level (Table I).

\begin{tabular}{|l|c|c|}
\hline Age range & Number & Percentage \\
\hline$<20$ years & 5 & 21.74 \\
\hline $20-30$ years & 15 & 65.22 \\
\hline $30-40$ years & 3 & 13.04 \\
\hline Total & 23 & 100 \\
\hline
\end{tabular}

Table 1 : Maternal death by age group

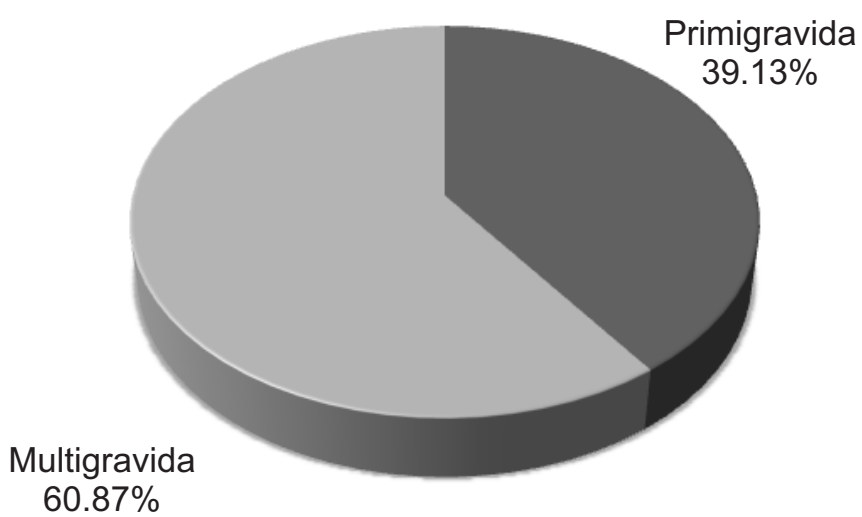

Figure 1 : Distribution according to gravida

It was seen that maternal death was more common in multigravidae women $(60.87 \%)$, in comparison to primigravida (39.13\%) Figure 1.

\begin{tabular}{|l|c|c|}
\hline Duration & Number & Percentage \\
\hline$<24$ hours & 6 & 26.1 \\
\hline $24-48$ hours & 4 & 17.4 \\
\hline$>48$ hours & 13 & 56.5 \\
\hline Total & 23 & 100 \\
\hline
\end{tabular}

Table II: Distribution by duration of hospitalization before death

It appears from Table II that $56.5 \%$ of deaths were occurring after 48 hours and $26.1 \%$ before 24 hours.

\begin{tabular}{|l|c|c|}
\hline Cause of death & Number $(\mathbf{n = 2 3 )}$ & Percentage \\
\hline Direct & 16 & 69.56 \\
\hline Indirect & 7 & 30.44 \\
\hline Total & 23 & 100 \\
\hline
\end{tabular}

Table III: Distribution of cases by cause of death

It was seen that maximum maternal mortality was because of direct obstetric causes (69.56\%) Table III.

\begin{tabular}{|l|c|c|}
\hline $\begin{array}{l}\text { Direct causes of } \\
\text { Death }\end{array}$ & Number & Percentage \\
\hline PPH & 6 & 37.5 \\
\hline Eclampsia & 3 & 18.75 \\
\hline Sepsis & 3 & 18.75 \\
\hline Preeclampsia & 2 & 12.5 \\
\hline DIC & 1 & 6.25 \\
\hline Ruptured uterus & 1 & 6.25 \\
\hline Total & 16 & 100 \\
\hline
\end{tabular}

Table IV: Distribution of Direct causes of death

Postpartum haemorrhage was the most common (37.5\%) direct cause of maternal mortality and heart failure was most common indirect cause. Table IV, V.

\begin{tabular}{|l|c|c|}
\hline $\begin{array}{l}\text { Indirect causes of } \\
\text { death }\end{array}$ & Number & Percentage \\
\hline Heart Failure & 3 & 42.86 \\
\hline Anaemia & 2 & 28.58 \\
\hline Renal failure & 1 & 14.28 \\
\hline Diabetes & 1 & 14.28 \\
\hline Total & 7 & 100 \\
\hline
\end{tabular}

Table V: Distribution of Indirect causes of death 


\section{DISCUSSION:}

In our study more than half of the women who died because of pregnancy related causes were in the age range of 20-30 years. These results were similar to the study of Odette et $\mathrm{al}^{5}$, Tebeu et al. $^{6}$, Pathak et $\mathrm{al}^{7}$ and Patel et $\mathrm{al}^{8}$. These could be because of marrying early, consequently, conceiving early. Sending young girls off in marriage is a big relief in some cultures such as in the Terai plains of Nepal where dowry is compulsory and where the dowry amount goes higher as unmarried girls grow older. Intracaste marriages are given a high priority in the Nepalese cultures and thus, parents may want to marry girls off sooner than later among such cultural groups for the fear of young unmarried daughters having affairs with men, especially with men from different castes. For Brahmin fathers, giving away a young daughter (Kanyadaan, literally meaning "virgin giveaway") means opening up the door to heaven. All these social customs may be affecting maternal mortality indirectly. Other cause could be because of lack of education in women regarding marriage and self-dependency among women ${ }^{4}$.

It was seen that maternal mortality was more common in multigravidae in comparison to primigravida this finding was similar to the study of Pathak et al ${ }^{7}$, Patel et $a^{8}{ }^{8}$. This could be because of lack of awareness about contraceptive practice to avoid unwanted pregnancy, as a result more MTPs by local untrained personnel for economic reasons and non-availability of appropriate specialist advice in due time has contributed to increased mortalities ${ }^{7,9}$.

In this study most of the women died after $48 \mathrm{hr}$ of hospital admission this may be because of some life saving measures started by hospital staff even patient reach hospital in already moribund state, this reflects more life saving strategies should have to be adopted in hospital. Complications of postpartum period may not be recognised by the family members, or may recognise only when the situation has gone from bad to worse ${ }^{4}$. In this study it was seen that direct obstetric causes was the leading cause of death this was similar to study of Odette et.al $\left.\right|^{5}$,Patel et.al ${ }^{8}$, Kodio et $\mathrm{al}^{10}$, Praul et $\mathrm{al}^{11}$ and Supratikto et. $\mathrm{al}^{12}$. Postpartum haemorrhage with $37.5 \%$ was the predominant cause; it remains a common and major cause also in African countries ${ }^{10,11}$. Hemorrhagic complications are sudden and unforeseeable and require a well-organized support; this involves material resources immediately accessible, competent and dynamic personnel; any delay or improvisation could contribute to a worsening of maternal prognosis. The haemorrhage is known for its rapid evolution towards a worsening (e.g. coagulopathy) and considerable blood loss requiring blood products ${ }^{5}$. Moreover, because haemorrhage was found to be the number one cause of maternal deaths in Nepal and because haemorrhage is related to anaemia, food rich in iron should be strongly recommended. Women do preserve different vegetables and foods for off season all over the country ${ }^{14}$.
Hypertensive diseases were the second leading cause of maternal deaths in this study these finding were similar to study of Odette et.al. ${ }^{5}$ and Patel et.al ${ }^{8}$. This study demonstrated increased odds of eclampsia in cases, which is in agreement with another study that found that the delay in diagnosis, triage, transport and treatment of eclampsia increases the risk of maternal death ${ }^{13}$. The management of severe hypertension requires organization of care and skill of the emergency team, specifically, a methodical treatment in the referral maternity. Improving antenatal care and identification of high risk cases and improving awareness about danger signs reduces mortality.

In this study sepsis was another common direct cause of maternal mortality. Maternal death from sepsis is mainly attributed to an increase in invasive group A streptococcal infections. Susceptibility to infection may be complicated by modulation of maternal immune response and increasing rates of risk factors such as caesarean section and obesity. Failure to recognize severity of infection is a major universal risk factor. Standardized Surviving Sepsis Campaign (SSC) recommendations for management of severe maternal sepsis are continuing to be implemented worldwide ${ }^{15}$.

On analysis of indirect cause heart disease, anaemia, diabetes was the common cause of maternal mortality. These findings were similar to study of Odette et al. ${ }^{5}$, Lumbiganon et. $\mathrm{al}^{16}$. Women with underlying indirect causes had significantly increased risks of severe maternal and perinatal outcomes. The causes of maternal mortality in our study are diverse, but in the majority of preventable cases almost $100 \%$. These findings provide strong support for prioritization of strategies that focus on professional intrapartum and postpartum care.

\section{CONCLUSIONS:}

Maternal mortality is a serious public health problem in Nepal and women have been dying of preventable reproductive causes. Haemorrhage, eclampsia and infections are the main causes of maternal deaths. The majority of these deaths occurred after 48 hours of admission. Unawareness of antenatal care and danger signs, the substandard care and delayed transfer of cases; which are avoidable were the three major contributing factors in these deaths.

Most of the deaths could have been avoided with good antenatal, intranatal and postnatal care, early referral, and quick, efficient and well equipped transport facilities, availability of adequate blood and blood components, and promotion of overall safe motherhood. The training should percolate among interns, house surgeons, residents and health guides too. Practice and knowledge of basic aseptic techniques is essential at all levels. Routine iron and folic acid supplementation is of proven value. 
Analysis of every maternal death through maternal death audit should be carried out. Community participation is more necessary. Awareness of birth control measures, sex education in adolescence can reduce deaths due to septic abortion.

\section{LIMITATIONS}

Limitations of this study are small sample size and short duration of study. Because of the diversified cultural practices and social norms that may have direct or indirect effects on women's health and mortality, studies should be done separately for major ethnic groups of Nepal.

\section{REFERENCES}

1. World Health Organization (1977) International Classification of Diseases, Revision 1975. World Health Organization, Geneva.

2. Shrestha R. Maternal mortality in Nepal: addressing the issue. Int J Health Sci Res. 2012;2(9):65-74.

3. Bhutta, Z. A., Darmstadt, G. L., Hasan, B. S., \& Haws, R. A. (2005). Community-based interventions for improving perinatal and neonatal health outcomes in developing countries: A review of the evidence. Pediatrics, 115(Supplement 2), 519-617. doi:10.1542/peds.2004-1441.

4. Suwal JV. Maternal Mortality in Nepal: Unraveling the Complexity. Canadian Studies in Population 2008;35(1):1-26.

5. Odette KM., Moise KK, Blood BND, Mukendi CP, Réne JMM., Kennedy NM. Et al. Etiologies of Maternal Mortality in the Hospital Provincial Janson Sendwe in Lubumbashi (DR. Congo). Open Access Library Journal. 2017;4:1-8 e3502. https://doi.org/10.4236/oalib.1103502.

6. Tebeu, P.M. Ngassa. P., Kouam, L., Major, G. and Fomulu, J.N. Maternal Mortality in Maroua Provincial Hospital, Cameroon . West Indian Medical Journal . 2007; 56: 502-507.

7. Pathak D, Chakraborty B, Goswami S, Adhikari S. Changing Trends of Maternal Mortality: A Comparative Study. The Journal of Obstetrics and Gynecology of India. 2011. March/April . 161-165

8. Patel M, Goswami K, Prajapati S, Chavda D. A five years retrospective analytic study of maternal deaths at tertiary care centre, Gujarat, India. Int J Reprod Contracept Obstet Gynecol 2016;5:2823-7.

9. Ahmed S, Li Q, Liu L, Tsui AO: Maternal deaths averted by contraceptive use: an analysis of 172 countries. Lancet 2012;380(9837):111-125.

10. Kodio B, Bernis L, Ba M., Ronsmans C, Pison G. Ltard JF. Levels and Causes of Maternal Mortality in Senegal. Tropical Medicine \& International Health. 2002; 7: 499-505. https://doi.org/10.1046/j.1365-3156.2002.00892.x

11. Prual A, Bouvier-Colle MH, Bernis D, Breart G. Severe Maternal Morbidity from Obstetric Causes Live in West Africa: Incidence and Case Fatality Rates. Bulletin of the World Health Organization. 2000; 78: 593-602.

12. Supratikto G, Wirth ME, Achadi E., Ronsmans C. A District- Based Audit into the Causes and Circumstances of Death Maternal in Southn Kalimantan, Indonesia. Bulletin of the World Health Organization. 2001; 80: 228-234.

13. Olopade F, Lawoyin T: Maternal mortality in a Nigerian maternity hospital. Afr J Biomed Res 2008, 11:267-273.

14. Bolam A, Manandhar DS, Shrestha P, Ellis M, Malla K, Costello AM. 1998. Factors affecting home delivery in the Kathmandu Valley, Nepal. Health Policy and Planning 13 (2): 152-158.
15. Acosta CD, Knight M. Sepsis and maternal mortality. Curr Opin Obstet Gynecol. 2013 Apr;25(2):109-16.

16. Lumbiganon $\mathrm{P}$, Laopaiboon $\mathrm{M}$, Intarut $\mathrm{N}$, Vogel JP, Souza JP, Gulmezoglu AM, et al. Indirect causes of severe adverse maternal outcomes: a secondary analysis of the WHO Multicountry Survey on Maternal and Newborn Health. BJOG 2014; 121 (Suppl. 1): 32-39. 